Jill Thorson*, Joan Borras-Comes, Verònica Crespo-Sendra, Maria del Mar Vanrell and Pilar Prieto

\title{
The acquisition of melodic form and meaning in yes-no interrogatives by Catalan and Spanish speaking children
}

\begin{abstract}
This study investigates the link between interrogative intonation and meaning in child-directed speech (henceforth CDS) and how this is reflected in the early development of yes-no-interrogatives of Catalan- and Spanish-speaking children. Previous research found that children before the two-word period produce several types of interrogatives and that their productions generally reflect the adult inventory pattern (Lleó \& Rakow 2011; Prieto et al. 2012). Yet prior studies have not included an analysis of the pragmatic meanings that are encoded intonationally. This investigation takes an integrated approach to the study of intonational development within the domain of yes-no questions, exploring further the correspondence between intonational form and meaning in early interrogative production and relating it to the pragmatics of interrogative intonation in child-directed speech. A set of 723 interrogative utterances produced by 3 Catalan- and 2 Spanish-acquiring children between the onset of interrogative production and 2;4 were pragmatically and then prosodically analyzed, as well as a set of 867 utterances from Catalan and Spanish CDS. The data were extracted from the Serra-Solé Catalan Corpus and the Ojea and López-Ornat Spanish Corpora in CHILDES. Production results show that all children perform some instance of questioning before the two-word period and that their productions generally reflect the adult inventory patterns. Moreover, the results show a preference relationship between the different types of nuclear pitch configurations and the pragmatic meanings that underlie the yes-no-interrogative forms. Finally, these results highlight the importance of the assessment of form-meaning relationships for the understanding of intonational development.
\end{abstract}

Keywords: pragmatics, intonation, intonational development, L1 acquisition 


\begin{abstract}
*Corresponding author: Jill Thorson: Department of Cognitive, Linguistic and Psychological Sciences, Brown University. E-mail: jill_thorson@brown.edu

Joan Borras-Comes, Verònica Crespo-Sendra: Departament de Traducció i, Universitat Pompeu Fabra, Ciències del Llenguatge, Spain

Maria del Mar Vanrell: Institut für Romanische Philologie, Freie Universität, Berlin, Germany Pilar Prieto: Institució Catalana de Recerca i Estudis Avançats (ICREA), Barcelona, Spain
\end{abstract}

\title{
1 Introduction
}

The emergence of intonational grammar in early speech has been shown to be temporally related to the onset of speech and the presence of a small lexicon (e.g., Chen \& Fikkert 2007, for Dutch; Frota \& Vigário 2008, for European Portuguese; Prieto \& Vanrell 2007; Prieto et al. 2012, for Catalan and Spanish). Frota and Vigário (2008) found that a European Portuguese child acquired the inventory of pitch accents and boundary tones in an adult-like way at 1;9 (years;months), with the emergence of such contours as early as 1;5. In their analysis of four Catalan children and two Peninsular Spanish children, Prieto et al. (2012) found that Catalan and Spanish children produce the basic phonologically distinct FO contours of their ambient language from the onset of their speech. Either a few months after the onset of speech or before the child reaches an age of two, each child exhibits a 'jump' in the number of nuclear configuration types, exhibiting an important knowledge of the adult intonational grammar. Even though these studies seem to point to an early acquisition of the target adult intonational forms by children, little is known about the acquisition of intonational meaning and whether the presence of these contours in early child speech correlate in discourse with specific semantic and pragmatic meanings.

Very few studies have analyzed the development of interrogative intonation (e.g., Lleó \& Rakow 2011; Armstrong 2012, for Spanish; Prieto et al. 2012, for Catalan and Spanish; among others). Some studies have concentrated on the acquisition of the phonetic properties of interrogative intonation, like Lleó and Rakow (2011), who showed that monolingual Spanish children do not produce the scaling properties of nuclear and prenuclear pitch accents in statements and interrogatives in a target-like way before three years of age. Armstrong (2012) investigated the acquisition of interrogative forms by two Puerto Rican Spanish toddlers between the ages of 19 and 43 months, taking into account the relationship between intonation form and meaning. The production results showed that children first acquire the default pitch contour encoding interrogativity. In addition, she finds evidence that children start producing two specialized con- 
tours that encode epistemic information in addition to interrogativity around 33 months. Still, little is known about the development of the melodic form and pragmatic meaning of interrogatives.

Recent research shows that the correspondence between pragmatic meaning and intonation is not as straightforward as once assumed. For adult speech, past literature suggested that there is a one-to-one mapping between pragmatic meaning and a specific intonational contour, with variation only introduced to reflect speaker information, such as class, age, or sex (Bolinger 1989). Bolinger (1989: 9) states "that the intonation configurations of which speakers avail themselves are the same for everyone, and the differences are in frequency and modulation.” Yet recent research looking more closely at the relationship between intonation and pragmatic meaning shows that form-meaning correspondences can be quite loose. Hirschberg and Pierrehumbert (1990: 284) discuss how specific intonation contours can adopt different pragmatic meanings depending on the discourse context rather than having a singular meaning unto themselves. For example, Ward and Hirschberg (1985) show how the same configuration of $\mathrm{L}^{\star}+\mathrm{H} \mathrm{LH} \%$ can be interpreted with irony, incredulity, politeness or certainty, depending on pragmatic context. Further work by Hirschberg (2002) considers intonational meaning to be a form of conversational implicature (in the Gricean sense) and that speakers can exploit common ground and shared knowledge in order to alter the interpretation of a specific intonational contour. For example, the rising boundary tone in English does not always reflect uncertainty or questioning, but it can be used ironically or rhetorically depending on the discourse context (Hirschberg 2002).

Other work on the interpretation of interrogatives in English shows that pragmatic context is essential in order to understand the intended meaning of a terminal rise (Gunlogson 2003). In Peninsular Spanish, Escandell-Vidal's (1998) proposal within Relevance Theory crucially links the role of intonation with context. One example discussed in this theory is the fall-rise contour. This contour is generally associated with a 'genuine question' interpretation, but it can also be used for rhetorical questions, indirect requests, or offers (Escandell-Vidal 1998). More recently, Armstrong (2012) showed that context is used as a mitigating factor in the interpretation of a nuclear contour type for interrogatives in Puerto Rican Spanish. In her study, she performed a series of perceptual experiments with adults showing how biasing a specific context will lead to different interpretations of the same nuclear contour type. Additionally, her work showed that there is a default interpretation when the contour is used in a neutral condition. There is thus a considerable amount of research that shows the complex nature of the mapping between intonational contour and pragmatic meaning, with discourse context playing an essential role. 
In this study, we take a comprehensive viewpoint to the analysis of yes-no interrogatives by considering in detail their form-meaning relationships. This investigation jointly explores the acquisition of intonation and meaning in early child speech and child-directed speech for yes-no interrogative utterances in a corpus of Catalan and Spanish natural child speech data. The goals of this study are threefold. First, we prosodically analyze yes-no interrogatives and their related pragmatic meanings as they appear in child-directed speech (CDS). Second, we also prosodically and pragmatically describe the yes-no interrogatives produced by three Catalan- and two Spanish-acquiring children between the ages of 1;5 and 2;4. Finally, we investigate the relationship between the intonational form of yes-no questions and their corresponding pragmatic meanings as produced by both children and adults. This work is part of a larger project on the early intonational development in Catalan- and Spanish-speaking children between the ages of $1 ; 0$ and 2;4. It represents an extension of the analysis of the general database, which is reported in Prieto et al. (2012).

Many languages have been shown to have intonational contours associated with different types of pragmatic meanings for yes-no (yn)-questions. The three most common pragmatic distinctions for the yes-no interrogative are between information-seeking questions, confirmation-seeking questions, and echo questions. While languages employ individual strategies to express these pragmatic distinctions, many often use prosody to distinguish between two or more of these pragmatic types. For example, languages including Cantonese, Italian, Japanese, and Portuguese use prosody to distinguish information- from confirmationseeking questions (Wong et al. 2005, for Cantonese; Grice et al. 2005; Savino \& Grice 2011, for Italian; Venditti et al. 2006, for English; Venditti 2005, for Japanese; Santos \& Mata 2008; Vigário \& Frota 2003, for Portuguese). Additionally, German, Chickasaw, and Swedish differentiate information-seeking from echo questions through their use of prosody (Grice et al. 2005, for German; Gordon 2005, for Chickasaw; House 2002, 2003, for Swedish). Interestingly, Spanish and Catalan are examples of languages that have been reported to exhibit intonational distinctions among all three of these types of yn-questions: confirmationseeking, information-seeking, and echo questions (Navarro Tomás 1968; Quilis 1985; Escandell-Vidal, 1998, for Spanish; Prieto 2014; Vanrell et al. 2013, for Catalan).

In this study, intonation patterns, both in child speech and in child-directed speech, will be analyzed from a prosodic point of view within the Autosegmental Metrical framework (henceforth, AM framework). As is well known, the AM model (Pierrehumbert 1980; Beckman \& Pierrehumbert 1986; Gussenhoven 2002; Jun 2005; Ladd 2008; among others) has become the most widely used phonological framework for analyzing intonation. With respect to its application to the 
analysis of child prosody, recent work has proven that this model is adequate to investigate the early intonation patterns in child speech, since early child productions have shown a consistent phonological association between tones and metrical structure (see Prieto et al. 2012; Prieto et al. 2011, for Catalan and Spanish; Chen \& Fikkert 2007, for Dutch; Frota \& Vigário 2008, for European Portuguese). We thus use an AM analysis to transcribe early intonation contours produced by Catalan and Spanish children.

\section{Methodology}

\subsection{Participants}

For the Peninsular Spanish data, the empirical bases of our investigations are the Ojea corpus and the López-Ornat corpus, both available in CHILDES. These contain the transcribed speech of two Peninsular Spanish speaking children, Irene of the Oviedo dialect and Maria of the Madrid dialect. Both families exclusively used Spanish in the home.

For the Catalan data we used the Serra-Sole corpus, also available in the CHILDES database. This corpus contains the transcribed speech of four Catalanacquiring children: Gisela, Guillem, Laura, and Pep. The families of all four of these children almost exclusively used Central Catalan within their family context. There was only limited contact with Peninsular Spanish outside the home. For this part of the study only Gisela, Guillem, and Laura were included in the analysis due to the fact that Pep did not produce any interrogatives during the analyzed age range.

The study's speech and video data on each child were compiled and submitted into the PhonBank database. PhonBank extends a given CHILDES database in the domain of phonetics and phonology and contains video files, sound files, and some phonological transcriptions (MacWhinney 1992; Rose et al. 2006; Rose \& MacWhinney, 2014).

\subsection{Materials}

The data analyzed for this study were taken from a larger project studying the acquisition of intonation in Spanish- and Catalan-acquiring children. For this part of the study, the data utilized went from the age at which each child uttered their first $y$-questions (between 1;5 and 1;7) through 2;4. Additionally, the $y n$ interrogatives of the adults present in the play sessions with the children were 
Table 1: Summary of participant's data.

\begin{tabular}{llll}
\hline & $\begin{array}{l}\text { Child Age at First } \\
\text { Interrogative } \\
\text { (MLUw) }\end{array}$ & $\begin{array}{l}\text { \# of Child YN- } \\
\text { Interrogatives } \\
\text { (onset of } \\
\text { interrogative to 2;4) }\end{array}$ & $\begin{array}{l}\text { \# of CDS YN- } \\
\text { Interrogatives } \\
(1 ; 7-2 ; 3)\end{array}$ \\
\hline Irene & $1 ; 5(1.5)$ & 23 & 102 \\
María & $1 ; 7(2.0)$ & 414 & 243 \\
Total Spanish & & 437 & 345 \\
\hline Guillem & $1 ; 9(1.3)$ & 106 & 279 \\
Pep & $\mathrm{N} / \mathrm{A}$ & 0 & 243 \\
Laura & $1 ; 9(1.1)$ & 71 & $\mathrm{~N} / \mathrm{A}$ \\
Gisela & $1 ; 8(1.0)$ & 109 & $\mathrm{~N} / \mathrm{A}$ \\
Total Catalan & & $\mathbf{2 8 6}$ & $\mathbf{5 2 2}$ \\
\hline
\end{tabular}

analyzed when the children were 1;7, 1;9, 1;11, 2;1 and 2;3. The speech from the adults of the two Spanish-speaking children and two of the adults from the Catalan-speaking children were analyzed. The form-meaning correspondences obtained for the child-directed $y n$-interrogatives were used as a baseline of comparison for the children data, as well as to provide an analysis of how Spanish and Catalan adults use interrogative intonation.

Table 1 presents a summary of the data used from both the children and the adults including the age of the child's first interrogative, the child's Mean Length Utterance in words (MLUw) at the age of their first interrogative (given in parentheses), the number of $y n$-interrogatives uttered by the child during that age range (from the onset of interrogative production until 2;4), and finally the number of child-directed speech (CDS) interrogatives uttered to the child between the ages of 1;7 and 2;3. The MLUw (Table 1) reflects the average number of words that make up an utterance for a child at a particular age. In this case, the MLUw shows that all of the children exhibit interrogatives well before they reach an MLUw of 2.0, the point at which they enter the two-word stage. María does not have data available in the corpus before age 1;7, where she already exhibits an MLUw of 2.0, so it is not possible to state when her first interrogative actually was uttered. As shown in Table 1 and mentioned in Section 2.1, the Catalan-speaking child Pep was not included in the child speech analysis due to his lack of interrogative production during this age range. However, the CDS data of Pep's caregivers were analyzed and those data are included in the final analysis. Due to the large amount of CDS data available and analyzed from Guillem and Pep's caregivers, none of the CDS data from Laura and Gisela's caregivers were analyzed. 


\subsection{Prosodic and pragmatic analyses}

The interrogative data were segmented and transcribed pragmatically using Phon (Rose et al. 2006) and prosodically analyzed using Praat (Boersma \& Weenink 2009). The coding of the pragmatics and the prosody was performed separately so as to not have the pragmatic interpretation affect the choice of the nuclear configuration contour. The same transcriber coded the pragmatic types and the prosodic labels for a given child. The transcribers met weekly over the course of a semester in order to discuss the coding and maintain a consensus for both the pragmatic and prosodic transcriptions. These meetings served as training sessions to better identify melodies and pragmatic classes. The authors of this study performed all transcriptions.

Furthermore, an inter-transcriber reliability test for the labeling of intonation was performed on a subset of the transcriptions from the originally analyzed data set of utterances from these corpora. A total of 80 randomly selected utterances from the children's databases were labeled prosodically by three independent transcribers using the Cat_ToBI and Sp_ToBI systems. A comparison of the tonal transcription across the three transcribers revealed a $77 \%$ consistency in pitch accent and boundary tone decisions, which confirms that the transcribers were quite reliable in their prosodic. See Prieto et al. (2012) for a more detailed description on reliability measures and statistics of the analyzed corpora.

\subsubsection{Pragmatic analysis}

An expanded range of pragmatic types, based initially on Escandell-Vidal's (1998) analysis, was used to categorize the $y n$-interrogative utterances. Specifically, the five pragmatic types used in this analysis were based on a combination of work by Holzman (1972), Sosa (1999), and the Map Task system (Anderson et al. 1991; Carletta et al. 1995). The five different pragmatic types for $y n$-questions are: information-seeking, confirmation-seeking, offers, pure echoes, and presumptive (or counter-expectational) echoes. Table 2 summarizes these pragmatic types and gives their definitions, as well as an example of each kind in English.

In Phon, we used eight tiers to code the data for each interrogative utterance. The tier labels are as follows: 1) Speaker (Name) 2) Orthography, 3) IPA Target, 4) IPA Actual, 5) Segment Time/Duration, 6) Response, 7) Pragmatic Meaning, and 8) Intention. The first tier provides the name of the subject under analysis. The second, third and fourth tiers give the orthographic transcription, the phonetic target in IPA transcription, as well as the actual phonetic production in IPA transcription of the selected $y n$-interrogative utterance. The fifth tier was 
Table 2: List of pragmatic types with representative examples from English.

\begin{tabular}{|c|c|}
\hline Pragmatic Type & Example \\
\hline $\begin{array}{l}\text { Information-seeking (I): Unmarked questions, } \\
\text { asking about new information }\end{array}$ & "Does John like oranges?” \\
\hline $\begin{array}{l}\text { Confirmation-seeking }(C) \text { : Questions that seek } \\
\text { assurance to something that is given or old } \\
\text { information. Testing for knowledge when the } \\
\text { speaker already knows the response (old } \\
\text { information) }\end{array}$ & $\begin{array}{l}\text { "So Maria is going to the party too?" } \\
\text { "So is that the color red?" }\end{array}$ \\
\hline $\begin{array}{l}\text { Offers (O): Question to solicit an offer or } \\
\text { invitation to the listener. Also includes Requests }\end{array}$ & $\begin{array}{l}\text { "Do you want a piece of candy?" } \\
\text { "Will you get the book?" }\end{array}$ \\
\hline $\begin{array}{l}\text { Pure Echos (E): Repetition of all or part of a } \\
\text { phrase when the speaker has not heard clearly; } \\
\text { also called 'reiteratives' in the Romance literature }\end{array}$ & $\begin{array}{l}\text { Context: During a conversation in a loud } \\
\text { restaurant, a listener does not clearly } \\
\text { hear the subject of an utterance: "The } \\
\text { bear turned the handle?" }\end{array}$ \\
\hline $\begin{array}{l}\text { Presumptive Echos }(P) \text { : Those that convey } \\
\text { incredulity and counter-expectational meanings }\end{array}$ & $\begin{array}{l}\text { Context: Upon hearing that a friend with a } \\
\text { broken leg walked to the store alone, you } \\
\text { question: "You walked with only one leg?" }\end{array}$ \\
\hline
\end{tabular}

generated automatically by Phon and displays the start and end time of the analyzed segment taken from the larger session. The sixth tier gives the response to the interrogative, which aided in verifying the pragmatic type from its discourse context. The seventh tier gives the pragmatic type label (see Table 2), and the eighth and final tier allows the transcriber to identify the speaker's actual contextual intent for that interrogative. For this subset of data, all of the utterances were of the $y n$-interrogative type. Figure 1 shows an example of this labeling schema in Phon. The labeling schema described above was used for each utterance.

\subsubsection{Prosodic analysis}

Importantly, each interrogative utterance was independently exported for a separate acoustic and prosodic analysis in Praat (Boersma \& Weenink 2009), following the Cat_ToBI and Sp_ToBI transcription systems (see Prieto 2014, for the most recent version of Cat_ToBI; Estebas-Vilaplana \& Prieto 2010 and Hualde \& Prieto to appear 2015, for the most recent version of Peninsular Spanish Sp_ToBI). Since all of the utterances were prosodically analyzed separately from the pragmatics, context did not influence the nuclear contour selection of the transcriber. 

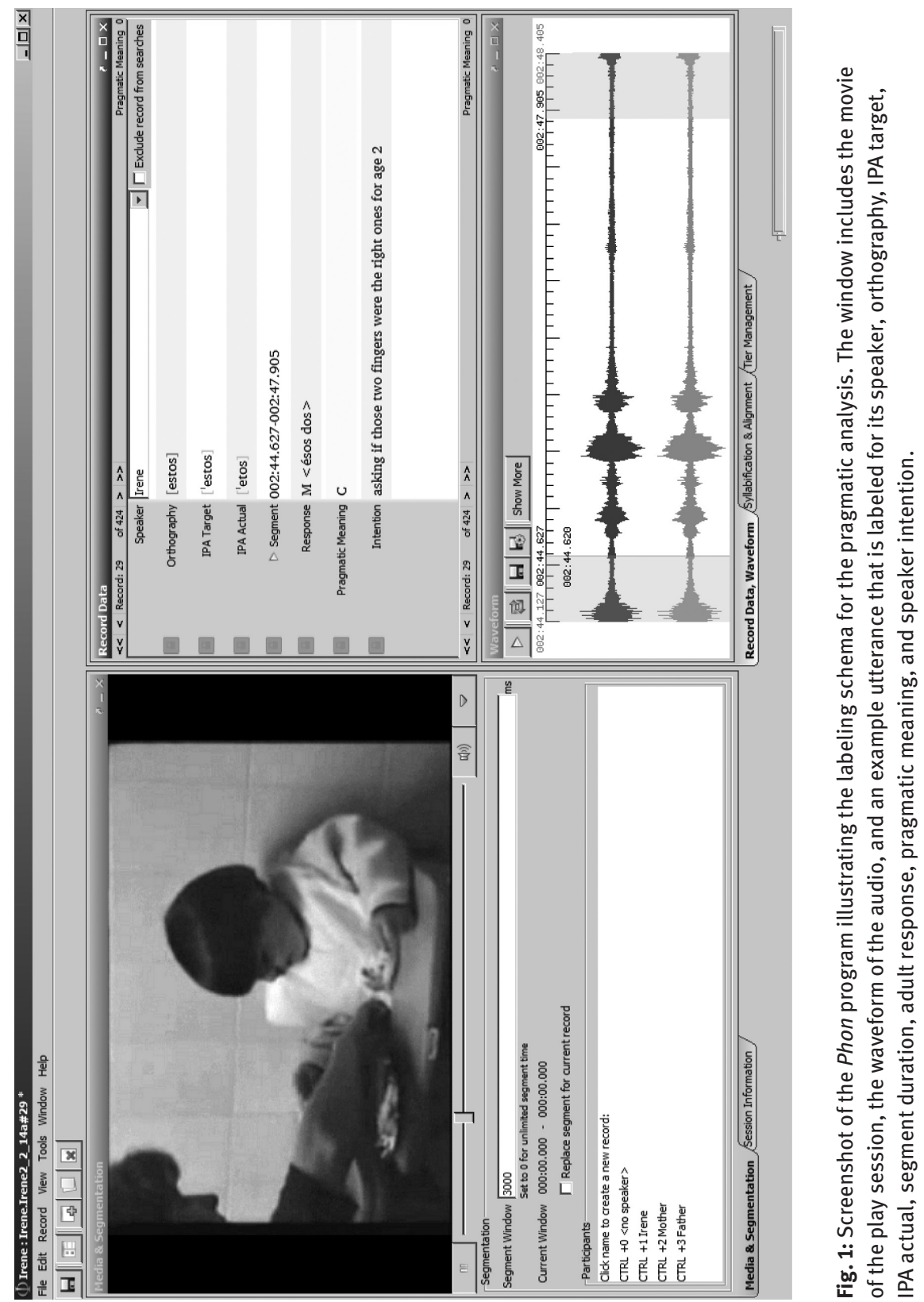
Traditional studies describe the standard $y n$-question intonation in Peninsular Spanish as having a low-rising configuration, $L^{\star} \mathrm{H} \%$ (e.g., Navarro Tomás 1968: 135; Quilis 1993: 414). Further studies though have identified three patterns for $y n$-questions including a rising contour $\left(\mathrm{L}^{\star} \mathrm{H} \%\right)$, a high-rise contour $\left(\mathrm{L}+\mathrm{H}^{\star} \mathrm{H} \%\right)$, and a circumflex contour, which has a rising-falling pattern after the initial descent $\left(\mathrm{L}_{\mathrm{i}} \mathrm{H}^{\star} \mathrm{L} \%\right)$ (Sp_ToBI transcriptions are given in parentheses) (Fernández Ramírez 1957-1959; Escandell-Vidal 1998). Specifically for Spanish, Escandell-Vidal (1998) proposes an analysis of these three contours within Relevance Theory and through the notion of procedural encoding, assigning a dominant pragmatic interpretation to each contour type (Wilson \& Sperber 1993). Intonation is assumed to be a 'procedural expression', that is, it encodes the constraints on the inferential phase of comprehension by restricting the range of possible interpretations of a sentence. Thus, Escandell-Vidal (1998) interprets the three nuclear contour types and their related meanings for the $y n$-interrogatives in Spanish. These three types are information-seeking questions, confirmationseeking questions, and both pure and presumptive echo questions. Table 3 presents a summary of these three preferred interpretations in adult Spanish, as well as their corresponding tonal nuclear configuration (for a more comprehensive description, see Estebas-Vilaplana \& Prieto 2010 and Hualde \& Prieto to appear

Table 3: Summary of $y n$-question nuclear contour types in Peninsular Spanish.

\begin{tabular}{lll}
\hline YN-Question Type & $\begin{array}{l}\text { Nuclear Configuration } \\
\text { (S__ToBl annotation) }\end{array}$ & Dominant Pragmatic Meaning \\
\hline Information-seeking & Information-seeking questions \\
\hline $\begin{array}{l}\text { Confirmation-seeking } \\
\text { Offer/Request }\end{array}$ & $\begin{array}{l}\text { Speaker conveys that s/he has some } \\
\text { knowledge about the answer; also, } \\
\text { offer/request/invitation }\end{array}$ \\
\hline $\begin{array}{l}\text { Pure and Presumptive } \\
\text { Echoes }\end{array}$ & $\begin{array}{l}\text { Speaker echoes the thought } \\
\text { attributed to someone else }\end{array}$ \\
\hline
\end{tabular}


2015). For example, the high-rising nuclear configuration, namely $\mathrm{L}+\mathrm{H}^{\star} \mathrm{H} \%$ opposed to the rising $\mathrm{L}^{\star} \mathrm{H} \%$ configuration, has been characterized as suggesting a cooperative meaning (i.e., the speaker and the listener know something about the answer; there is a sense of mutual assistance), especially in child-directed speech (Escandell-Vidal 1998).

The table provides the $y n$-question pragmatic type, the schema of the nuclear configuration and its Sp_ToBI label, and a general semantic description of the dominant pragmatic meaning for each contour type.

For Catalan, research has revealed four different $y n$-interrogative nuclear configuration types (Bonet 1986; Prieto 2002; Prieto 2014). These four types include the three nuclear configuration types (rising, high-rise, and rising-falling) found in Spanish as well as an additional fourth kind: a falling pitch contour pattern typically interpreted as a confirmation-seeking question $\left(H+L^{\star} \mathrm{L} \%\right)$.

Table 4: Summary of $y n$-question nuclear contour types in Central Catalan.

\begin{tabular}{lll}
\hline YN-Question Type & $\begin{array}{l}\text { Nuclear Configuration } \\
\text { (Cat_ToBl annotation) }\end{array}$ & Dominant Pragmatic Meaning \\
\hline $\begin{array}{l}\text { Information-seeking } \\
\text { \& Presumptive Echo) }\end{array}$ & $\begin{array}{l}\text { Information-seeking question } \\
\text { (or, Speaker echoes the thought } \\
\text { attributed to someone else with } \\
\text { incredulity) }\end{array}$ \\
\hline Confirmation-seeking & $\begin{array}{l}\text { Speaker conveys that s/he has } \\
\text { some knowledge about the } \\
\text { answer }\end{array}$ & \\
\hline
\end{tabular}

Pure Echo

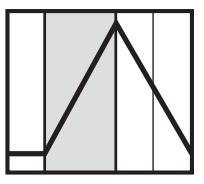

$\mathrm{L}+{ }_{\mathrm{i}} \mathrm{H}^{*} \mathrm{~L} \%$

Offer/Request/Inviting

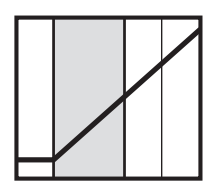

$\mathrm{L}+\mathrm{H}^{*} \mathrm{H} \%$
Speaker echoes the thought attributed to someone else

Speaker conveys a more polite form in an effort to offer, request or invite 


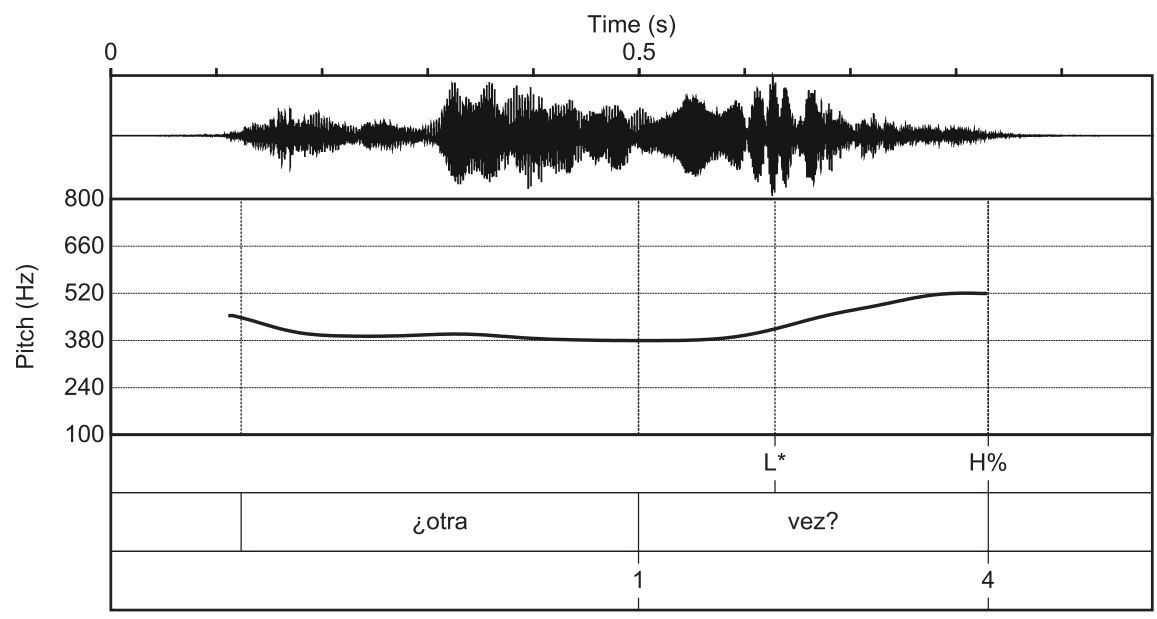

Fig. 2: Waveform, spectrogram, F0 contour, tonal transcription, orthographic transcription, and strength of prosodic boundaries in the phrase “¿Otra vez?” 'Again?' uttered by Irene at 1;6.

Table 4 presents a summary of the commonly occurring nuclear pitch configurations of interrogative utterances in adult Central Catalan.

Figure 2 shows an example of the orthographic and prosodic transcription for the utterance “Otra vez?” 'Again?' produced by Irene at age 1;6 with an $L^{\star} \mathrm{H} \%$ nuclear configuration, which includes both a nuclear pitch accent $\left(\mathrm{L}^{\star}\right)$ and a boundary tone (H\%). The Praat image gives the spectrogram, F0 track, and the waveform of the utterance as well as a TextGrid displaying information about the utterance. In the Praat TextGrid, the first tier displays the tonal transcription for the utterance while the second gives the orthographic transcription of the utterance. Finally, the third tier shows the strength of the prosodic boundaries (on a scale from 0 to 4 with 0 representing no break and 4 representing the boundary at the end of an Intonational Phrase). An optional fifth tier (not displayed) was also available for the transcriber to note any comments about the utterance (e.g., child-directed speech characteristics).

\section{Results}

Results for the prosodic and pragmatic analyses of the $y n$-interrogative corpus data are presented for both the child-directed speech (CDS) and the children data. In each of these sections, the Peninsular Spanish data results are presented first followed by the Central Catalan data results. 


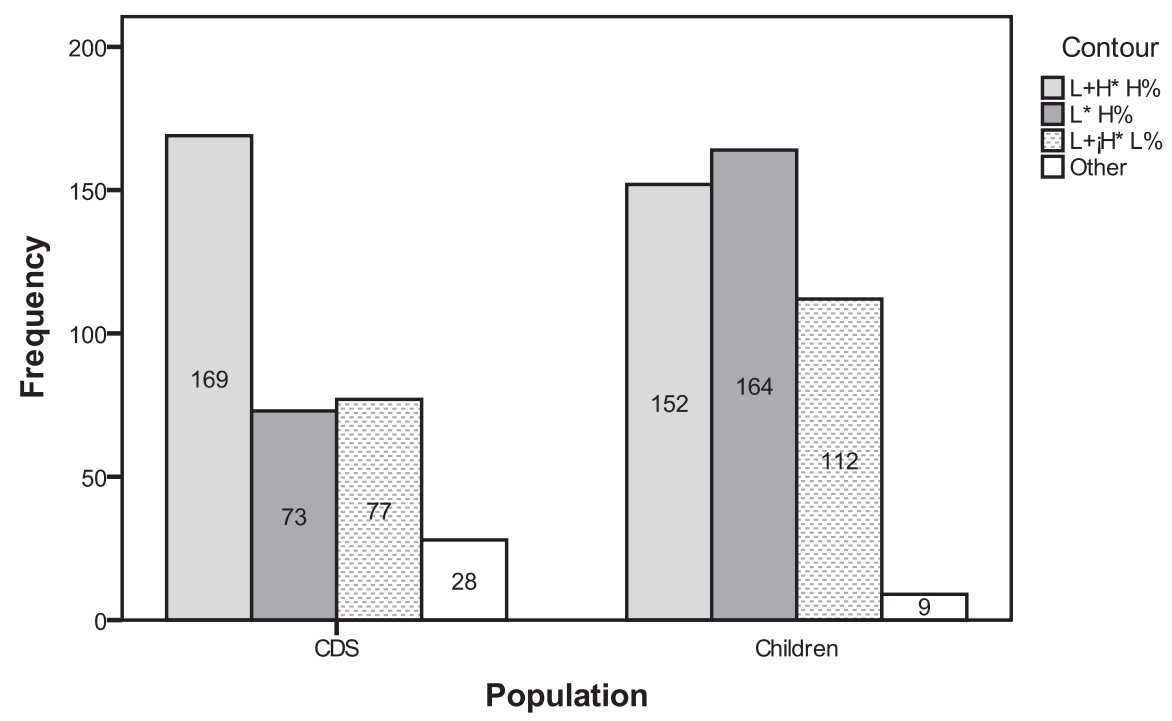

Fig. 3: Frequencies of nuclear configuration types for yn-interrogatives in Peninsular Spanish CDS and child speech.

\subsection{Child-directed speech results}

\subsubsection{Peninsular Spanish}

Six different nuclear configuration types were identified in the target interrogative sentences in the child-directed speech, with the three primary types for $y n$ interrogatives in Spanish making up 92 percent of the nuclear configuration contours (i.e., $\mathrm{L}^{\star} \mathrm{H} \%, \mathrm{~L}+\mathrm{H}^{\star} \mathrm{H} \%$, and $\mathrm{L}+{ }_{\mathrm{j}} \mathrm{H}^{\star} \mathrm{L} \%$; see Table 3). First, Figure 3 shows the frequencies of each of the nuclear configuration types found in both the CDS and the child speech. (The child speech results for Spanish will be discussed in detail in Section 3.2.1). Typically, child-directed intonational contours are produced with an increased pitch range, lengthened duration, register shift, and/or final mid boundary tones, all characteristics of child-directed speech. The results for the Spanish CDS interrogatives only (i.e., not the Catalan CDS) are reported more extensively in Prieto et al. (2011).

Second, Figure 4 shows the distribution of pragmatic meanings that have been typically associated with these three contours. The five pie graphs in Figure 4 show the nuclear contour patterns observed for each of the pragmatic types analyzed. In each pie graph, the pitch contour percentage that has been commonly associated in the literature to that pragmatic type is bolded as a reference 


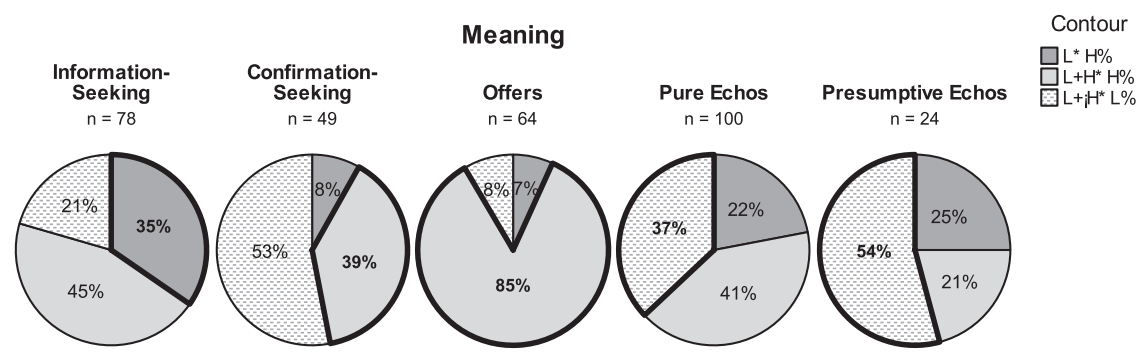

Fig. 4: Pie graphs depicting the percentages of occurrence of the nuclear configuration contours for each of the five pragmatic types in Spanish CDS. The percentage that commonly corresponds with the contour for each pragmatic type is bolded.

point (see Table 3 for a full list of the nuclear configuration contours in Peninsular Spanish and their commonly corresponding pragmatic types). These results show that multiple contour types were associated with each of the $y n$-interrogative pragmatic types, indicating that there is no one-to-one nuclear configuration pattern to pragmatic type mapping. For example, it is evident from the pie graphs in Figure 4 that $\mathrm{L}+{ }_{i} \mathrm{H}^{\star} \mathrm{L} \%$ is a productive nuclear configuration pattern in Spanish CDS and is used for every pragmatic type with varying degrees of frequency.

The nuclear configurations hypothesized in previous literature to correspond to each pragmatic type were in fact found to be prominent (but not always dominant) patterns in the Spanish CDS (Figure 4). Following the observations made in the literature, offer interrogatives were most frequently represented by $\mathrm{L}+\mathrm{H}^{\star} \mathrm{H} \%$; presumptive echoes were also commonly associated with $\mathrm{L}+\mathrm{j} \mathrm{H}^{\star} \mathrm{L} \%$. Both of these results support the observation by other researchers outlined in the introduction. In a point of divergence from previous literature, however, for informationseeking interrogatives, the most frequently identified nuclear configuration type was actually the $\mathrm{L}+\mathrm{H}^{\star} \mathrm{H} \%$, with $45 \%$ of the data, while the typically associated $\mathrm{L}^{\star}$ $\mathrm{H} \%$ pattern accounted for $35 \%$ of the data. For confirmation-seeking interrogatives, the expected associated contour was $\mathrm{L}+\mathrm{H}^{\star} \mathrm{H} \%$, appearing in $39 \%$ of cases. However, the most frequent type for confirmation-seeking interrogatives was the $\mathrm{L}+\mathrm{i} \mathrm{H}^{\star} \mathrm{L} \%$ pattern, accounting for $53 \%$ of the data. For echo questions, two nuclear configuration patterns were found with relatively equal frequencies: the expected $\mathrm{L}+{ }_{\mathrm{i}} \mathrm{H}^{\star} \mathrm{L} \%$ in $37 \%$ of the data and the $\mathrm{L}+\mathrm{H}^{\star} \mathrm{H} \%$ contour in $41 \%$ of the data.

\subsubsection{Central Catalan}

Figure 5 provides the frequencies of each of the nuclear configuration types found in the spontaneous speech data analyzed for both the CDS and the child speech 


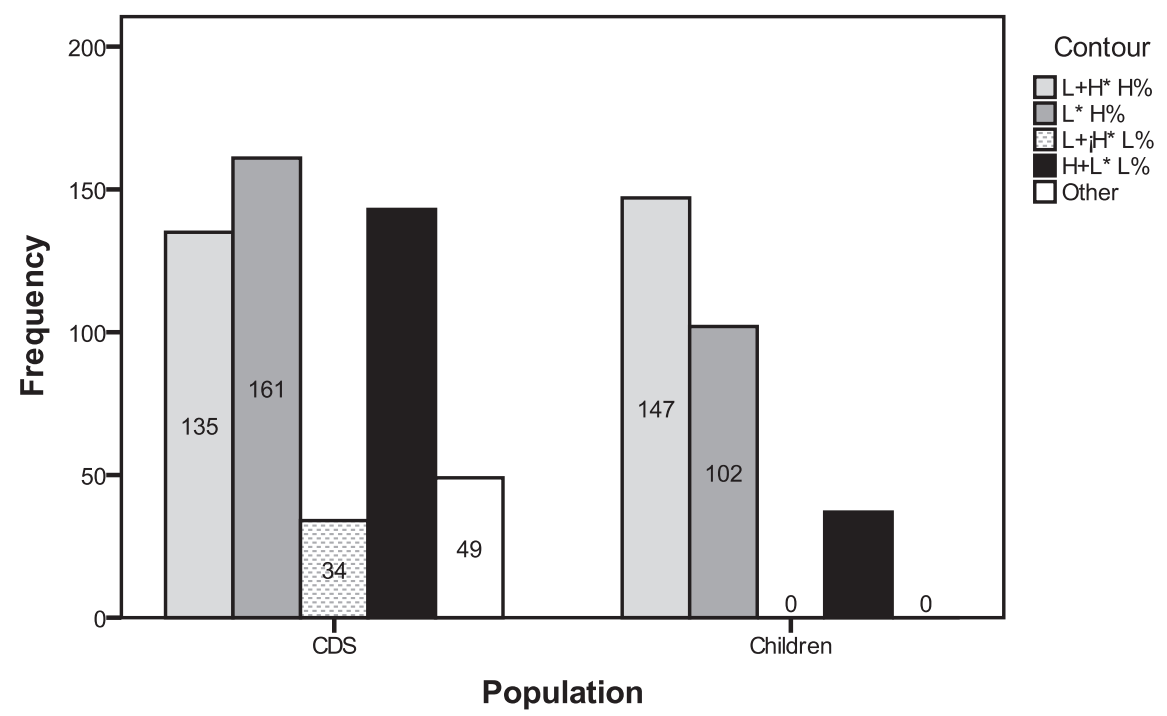

Fig. 5: Frequencies of nuclear configuration types for yn-interrogatives in Central Catalan CDS and child speech.

for Catalan. Six different nuclear configuration types were identified in the Central Catalan CDS, with the four types associated with yn-interrogatives (see Table 4), making up 91 percent of the data. (The child speech data for Catalan will be discussed in Section 3.2.2).

While Figure 5 shows the distribution of nuclear configuration types found across all instances of $y n$-interrogatives, Figure 6 illustrates the full breakdown of which nuclear contours are associated with each of the pragmatic types for the Central Catalan CDS. For each pragmatic type, a pie graph presents which nuclear configuration patterns were produced. As with the Peninsular Spanish data, the Central Catalan CDS shows that for each pragmatic type, there are a number of different nuclear contour patterns (Figure 6). For each of the five pragmatic types of Catalan yn-interrogatives, several nuclear configurations were identified. For information-seeking interrogatives, the commonly associated $\mathrm{L}^{\star} \mathrm{H} \%$ contour accounts for $61 \%$ of the data, with an additional $33 \%$ being accounted for by the other rising contour $\mathrm{L}+\mathrm{H}^{\star} \mathrm{H} \%$. Again, for confirmation-seeking questions, the most frequent nuclear configuration in the CDS was the $\mathrm{H}+\mathrm{L}^{\star} \mathrm{L} \%$, typically described in the literature. Also, offering questions were most frequently associated with the $\mathrm{L}+\mathrm{H}^{\star} \mathrm{H} \%$ nuclear configuration pattern. Both the pure and the presumptive echoes were most frequently realized by the $\mathrm{L}^{\star} \mathrm{H} \%$ contour, an association which was not identified by the literature. This pattern reinforces the idea 


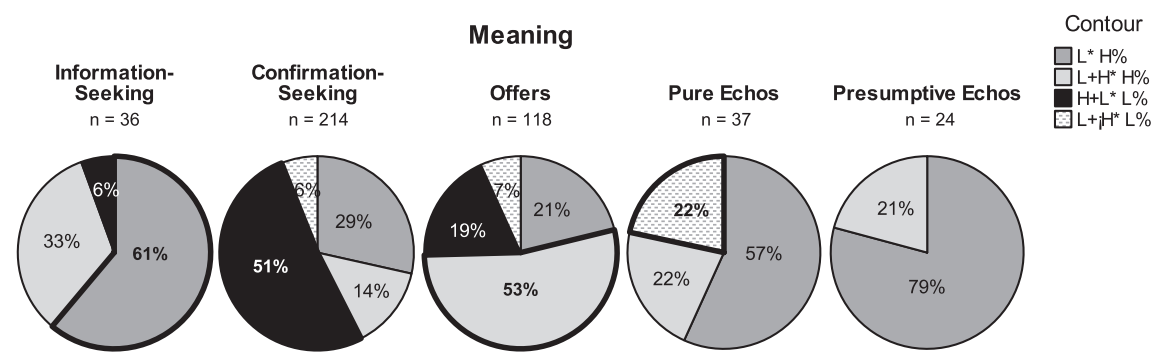

Fig. 6: Pie graphs depicting the percentages of occurrence of the nuclear configuration contours for each of the five pragmatic types in Central Catalan CDS. The percentage that commonly corresponds with the contour for each pragmatic type is bolded.

that the $\mathrm{L}^{\star} \mathrm{H} \%$ contour is serving multiple purposes in the Central Catalan CDS data, similar to the way the $\mathrm{L}_{\mathrm{i}} \mathrm{H}^{\star} \mathrm{L} \%$ and $\mathrm{L}^{\star} \mathrm{H} \%$ contours behave in the Peninsular Spanish CDS results.

\subsection{Child speech results}

\subsubsection{Peninsular Spanish}

The $y n$-interrogative nuclear configuration contours of $\mathrm{L}+\mathrm{H}^{\star} \mathrm{H} \%, \mathrm{~L}^{\star} \mathrm{H} \%$, and $\mathrm{L}+{ }_{\mathrm{i}} \mathrm{H}^{\star} \mathrm{L} \%$ were found to be the three most common contours in the children data. Referring back to Section 3.1.1, Figure 3 shows a bar graph depicting the frequencies of each of these three nuclear configuration type for the Peninsular Spanish-speaking children alongside the adults' child-directed speech. This graph indicates a preference for these three nuclear contours in $y n$-interrogatives for both the Spanish CDS and child speech. One difference between the two groups (meaning CDS and child speech) is the frequency of the $\mathrm{L}^{\star} \mathrm{H} \%$ pattern, which is more common in child speech.

Figure 7 gives the nuclear contour type distribution for each of the pragmatic types for the Spanish-speaking children. For information-seeking questions, the $\mathrm{L}^{\star} \mathrm{H} \%$ contour (the contour typically associated with this meaning in the literature) accounted for $43 \%$ of the child speech data. The high-rise contour $\mathrm{L}+\mathrm{H}^{\star} \mathrm{H} \%$ was the second most common for information-seeking questions, comprising $34 \%$ of the data. We noted a similar pattern in the CDS confirmation-seeking questions, with both of these contours representing the majority of the intonation contours associated with this meaning. In fact, confirmation-seeking and information-seeking interrogative results are more evenly distributed than offer ques- 


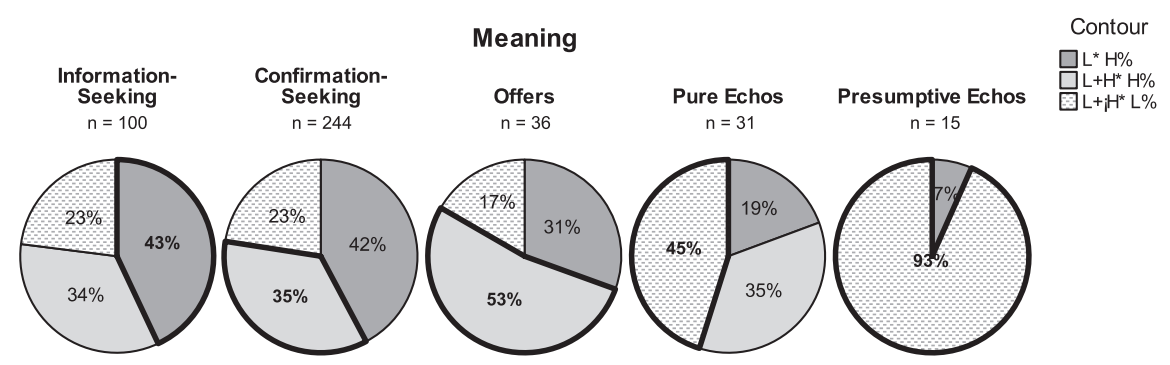

Fig. 7: Pie graphs depicting the percentages of occurrence of the nuclear configuration contours for each of the five pragmatic types in Peninsular Spanish child speech. The percentage that commonly corresponds (in the previous literature) with the contour for each pragmatic type is bolded.

tions amongst the three nuclear configuration types. The offer interrogatives support the findings of previous literature, with $\mathrm{L}+\mathrm{H}^{\star} \mathrm{H} \%$ as the most dominant pattern. The two types of echo interrogatives most often employ the $\mathrm{L}+\mathrm{i} \mathrm{H}^{\star} \mathrm{L} \%$ contour, showing that children use one of the most common adult contours within this pragmatic type (see Figure 4).

Examples of different pragmatic types found in the child corpus data, each matching the most frequent nuclear configuration for that type, are presented below in Figures 8, 9, and 10. Figure 8 shows the spectrogram, F0 track, and waveform of the child María at 2;2 uttering “¿Estás sentado?” 'Are you sitting?’, an

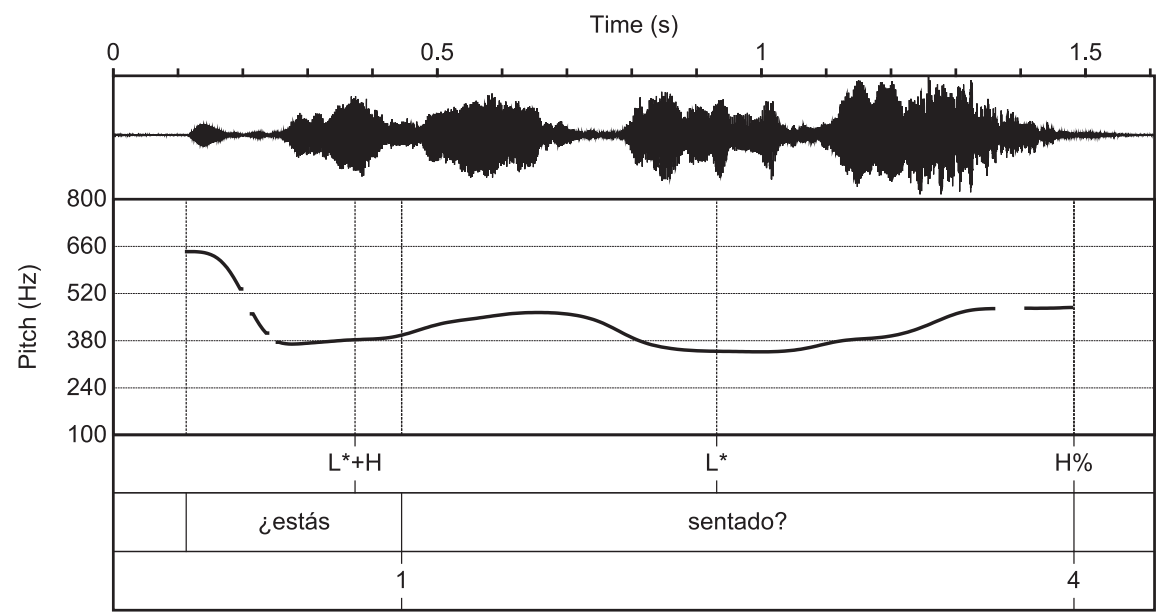

Fig. 8: Waveform, spectrogram, F0 contour and prosodic labeling of the information-seeking question “¿Estás sentado?” ‘Are you sitting?’ uttered by María at 2;2. 


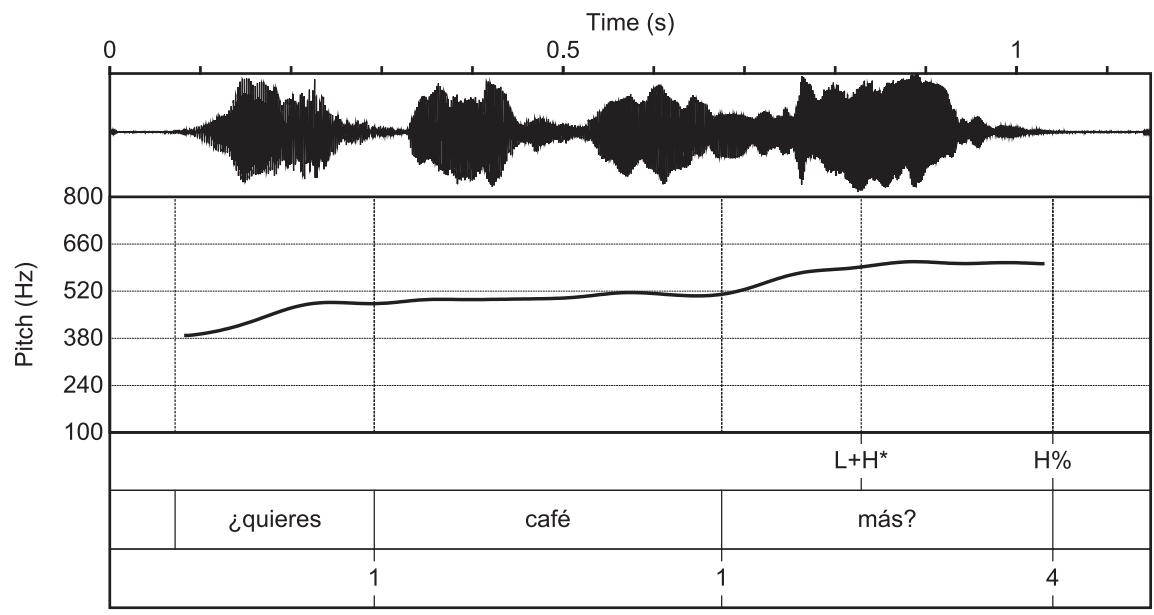

Fig. 9: Waveform, spectrogram, F0 contour and prosodic labeling of the offer/request “¿Quieres café más?” ‘Do you want more coffee?’ uttered by María at 2;2.

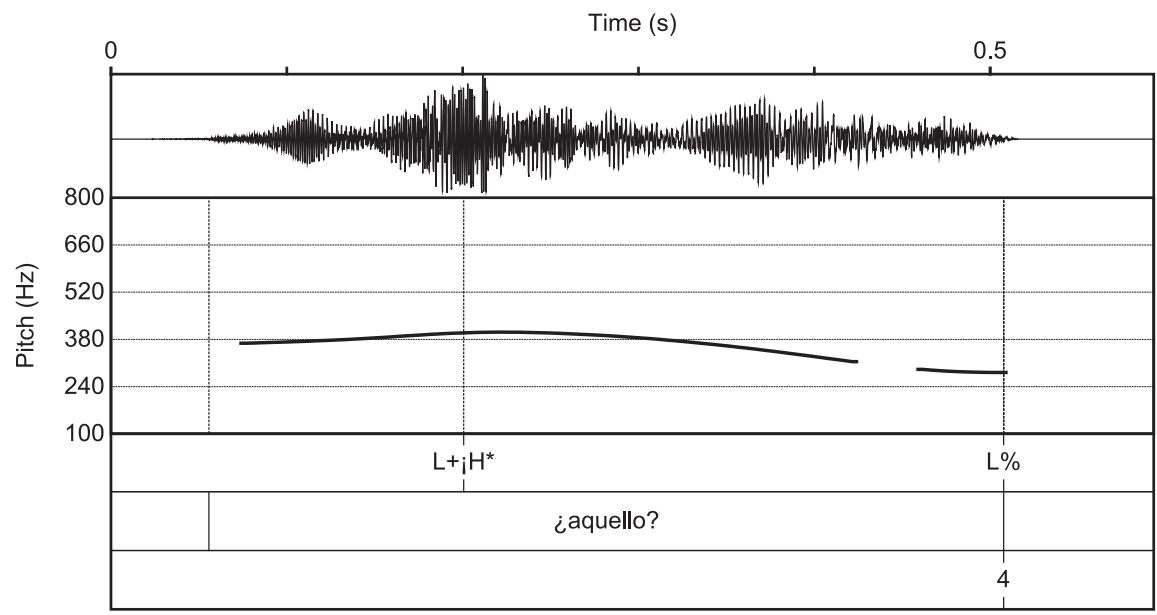

Fig. 10: Waveform, spectrogram, F0 contour and prosodic labeling of the echo question “¿Aquello?” 'That one?’ uttered by María at 2;2.

information-seeking question with the adult-like $\mathrm{L}^{\star} \mathrm{H} \%$ nuclear configuration type. The same child additionally utters “¿Quieres café más?” 'Do you want more coffee?', an offer or request pragmatic interpretation with the typical $\mathrm{L}+\mathrm{H}^{\star} \mathrm{H} \%$ nuclear configuration (Figure 9). Finally, an example of an echo question with the 
$\mathrm{L}+\mathrm{jH}^{\star} \mathrm{L} \%$ nuclear accent type is found in the question “Aquello?” 'That one?' said by María at 2;2 (Figure 10). Note that the context in which each question was stated as well as the response in return was taken into account when deciding on the pragmatic type and intention of the speaker.

\subsubsection{Central Catalan}

Figure 5 in Section 3.1.2 contains a bar graph depicting the frequencies of the distinct nuclear configuration types for both the child speech and adults' CDS data for Central Catalan. Only three of the four adult tonal nuclear configuration patterns were found in the Catalan children data: $\mathrm{L}+\mathrm{H}^{\star} \mathrm{H} \%, \mathrm{~L}^{\star} \mathrm{H} \%$, and $\mathrm{H}+\mathrm{L}^{\star} \mathrm{L} \%$ (missing is $\mathrm{L}+{ }_{i} \mathrm{H}^{\star} \mathrm{L} \%$ ). Of the three nuclear accent patterns analyzed, the $\mathrm{L}+\mathrm{H}^{\star}$ $\mathrm{H} \%$ made up $51 \%$ of the produced $y n$-interrogatives. The second most frequent nuclear accent was the $\mathrm{L}^{\star} \mathrm{H} \%$, making up $36 \%$ of the data, and finally the $\mathrm{H}+\mathrm{L}^{\star}$ $\mathrm{L} \%$ accounted for $13 \%$ of the data. The nuclear configuration pattern that was not produced by any of the children in this age range was $\mathrm{L}+{ }_{\mathrm{i}} \mathrm{H}^{\star} \mathrm{L} \%$, which was also very infrequent in the adult CDS data. By contrast, the Spanish data are quite different. Since the $\mathrm{L}+{ }_{j} \mathrm{H}^{\star} \mathrm{L} \%$ pattern appears quite frequently in the Spanish CDS data, Spanish children do use it frequently as well (see Figure 7 in Section 3.2.1).

The nuclear contour types found for each pragmatic type in Catalan child speech are shown in the pie graphs in Figure 11. The confirmation-seeking $\left(\mathrm{H}+\mathrm{L}^{\star}\right.$ $\mathrm{L} \%$ ), offers $\left(\mathrm{L}+\mathrm{H}^{\star} \mathrm{H} \%\right.$ ), and presumptive echo interrogatives ( $\mathrm{L}^{\star} \mathrm{H} \%$ ) all show a preference for the previously associated nuclear pattern correspondences put forth in previous literature and outlined in the introduction (Figure 11). For the information-seeking interrogatives, the children used the two rising contours

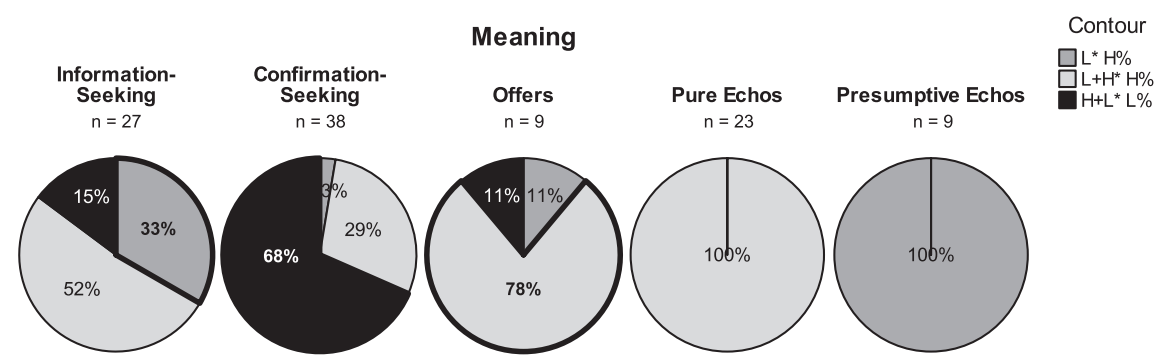

Fig. 11: Pie graphs depicting the percentages of occurrence of the nuclear configuration contours for each of the five pragmatic types in Central Catalan child speech. The percentage that commonly corresponds with the contour for each pragmatic type is bolded. 
$\mathrm{L}+\mathrm{H}^{\star} \mathrm{H} \%(52 \%)$ and $\mathrm{L}^{\star} \mathrm{H} \%$ (33\%) most frequently. This result importantly shows that there is still a priority for the rising contour types over the falling pitch contour $\mathrm{H}+\mathrm{L}^{\star}$ in both the adult and child data. The Central Catalan-acquiring children seem to have acquired the confirmation-seeking interrogatives with relatively high accuracy, as $68 \%$ of the confirmation-seeking questions are produced with a falling pitch contour (i.e., the $\mathrm{H}+\mathrm{L}^{\star} \mathrm{L} \%$ contour), which is the predominant pitch pattern found in the CDS results for confirmation-seeking questions. Similarly, offers are predominantly realized (in 78\% of the cases) with the expected $\mathrm{L}+\mathrm{H}^{\star} \mathrm{H} \%$ pitch contour. However, the child data differed substantially from the adult CDS for the pure echo questions. The children produced 100\% of the nuclear configuration patterns with the $\mathrm{L}+\mathrm{H}^{\star} \mathrm{H} \%$ contour, which was only $22 \%$ present in the adult CDS. The adults instead used the $\mathrm{L}^{\star} \mathrm{H} \%$ pattern for over half of the cases identified. The pure echo pattern of $\mathrm{L}+{ }_{\mathrm{i}} \mathrm{H}^{\star} \mathrm{L} \%$ was only found in $22 \%$ of cases in the adult CDS data and in none of the children utterances, even though this was the nuclear configuration pattern that the literature previously associated with pure echoes.

Next, we present example utterances from the Central Catalan child data, with each example showing the corresponding nuclear configuration for that type. The first example is comprised of two information-seeking questions, each with the typically associated L* H\%: "La Maria Rosa? De les fotos?" 'Maria Rosa? From the photos?' uttered by Guillem at age 2;1 (Figure 12). Figure 13 shows the spectrogram, F0 track, and waveform of the same child uttering “El Quim?” 'Quim

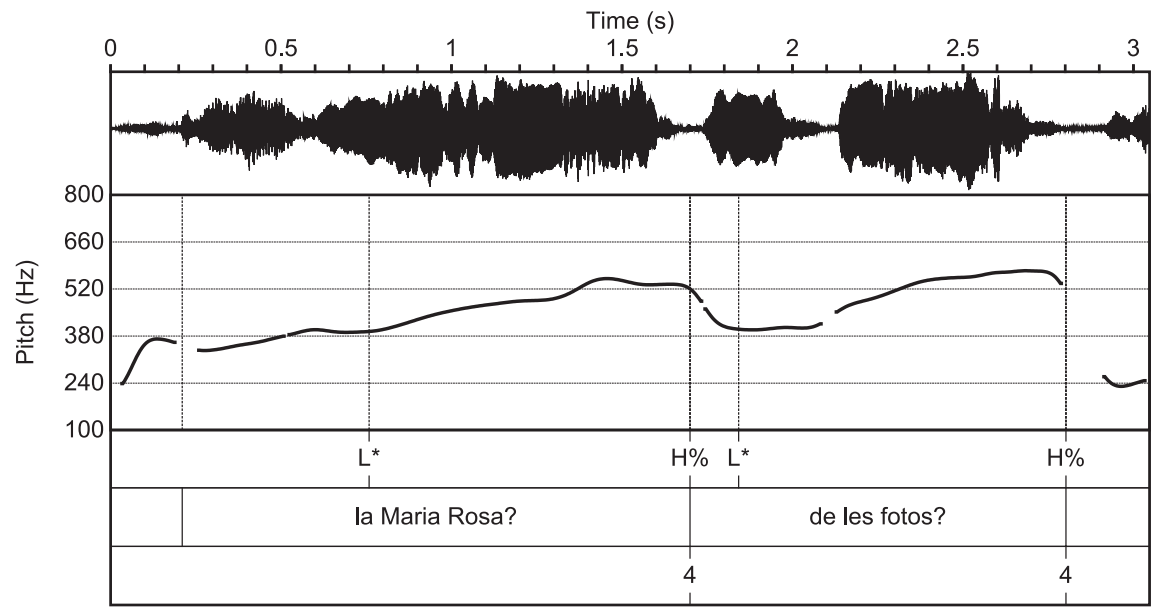

Fig. 12: Waveform, spectrogram, F0 contour and prosodic labeling of the information-seeking question “La Maria Rosa? De les fotos?” ‘Maria Rosa? From the photos?' uttered by Guillem at 2;1. 


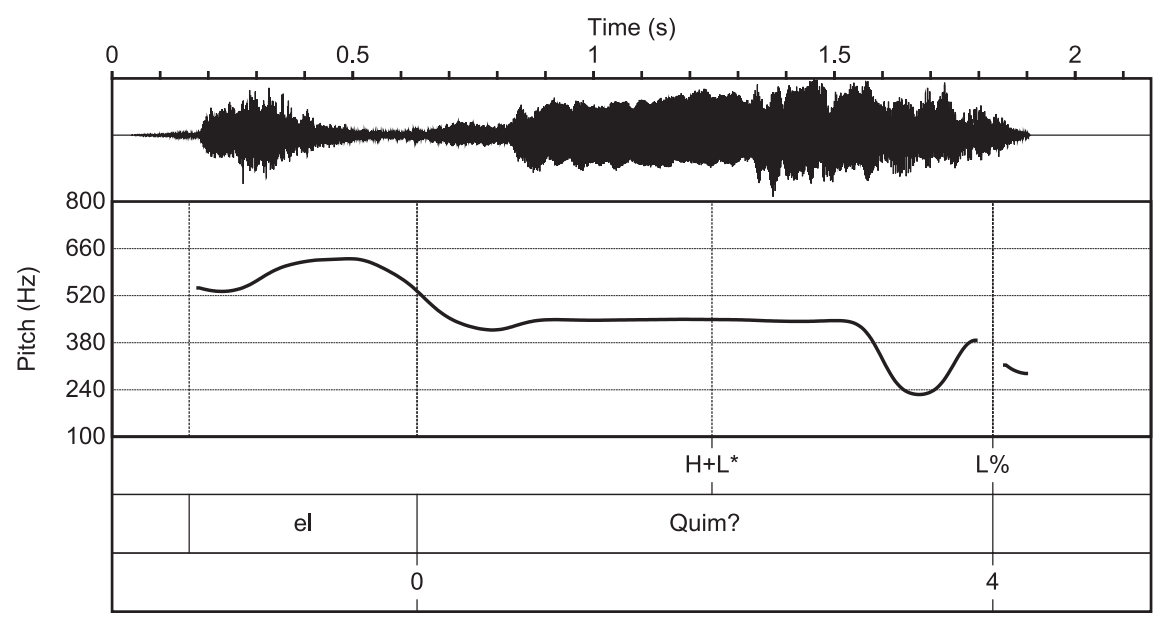

Fig. 13: Waveform, spectrogram, F0 contour and prosodic labeling of the confirmation-seeking question “El Quim?” ‘Quim [proper name]?’ uttered by Guillem at 2;1.

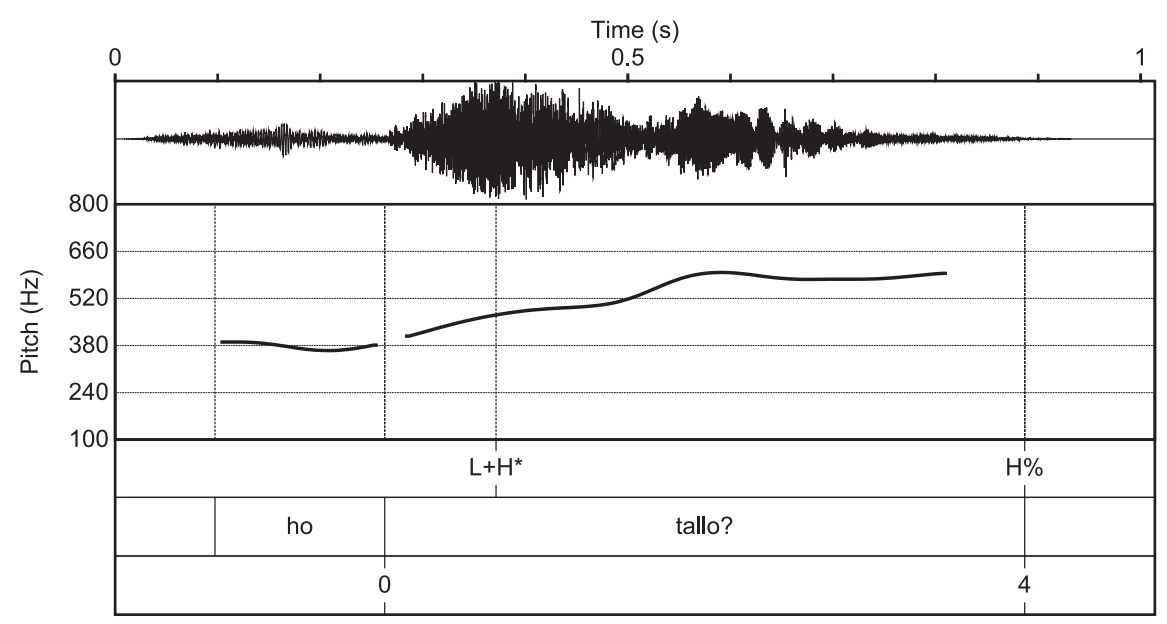

Fig. 14: Waveform, spectrogram, F0 contour and prosodic labeling of the offer/request “Ho tallo?" 'Can I cut it?' uttered by Guillem at 2;2.

[proper name]?', a confirmation-seeking question with the adult-like falling $\mathrm{H}+\mathrm{L}^{\star}$ L\% nuclear configuration type. Finally, the last utterance is "Ho tallo?" 'Can I cut it?' said by Guillem at age 2;2 and is an example of an offer or request with the typical $\mathrm{L}+\mathrm{H}^{\star} \mathrm{H} \%$ nuclear configuration pattern (Figure 14). 


\section{Discussion and conclusions}

This article has examined a set of 723 utterances from three Catalan-speaking children and two Spanish-speaking children between the ages of approximately 1;5 and 2;4, focusing on the acquisition of form and meaning of interrogative forms in spontaneous interactions. This is the first study to analyze the interrogative pragmatic type/pitch contour mapping in spontaneous speech in Central Catalan and Peninsular Spanish. Critically, the study has compared the results on the correspondences between pragmatic meaning and pitch contour in child speech with those found in child-directed speech data (a total of 867 utterances) from the same corpora.

Both the child speech and CDS were analyzed pragmatically and then independently analyzed prosodically in the AM framework (Pierrehumbert 1980). In this regard, the study has served to confirm that the use of the AM model in early speech offers an effective tool to investigate how children learn the languagespecific inventory of phonologically distinct intonation contours of the target language, supporting earlier work by Prieto et al. (2012). This study also lends additional credence to recent reports that F0 melodic contrasts are attained by children very early in production (Prieto \& Vanrell 2007; Astruc et al. 2013).

An analysis of the data shows that all of the children in the study performed instances of interrogative forms before the two-word period. This is with the exception of Maria, whose speech data begin when she has already entered the two-word period, and who has already shown uses of interrogatives at this point. It is likely, following the pattern of the other children, that María also used interrogatives earlier in her grammatical development. Second, the data show that child productions of yes-no interrogatives between 1;5 and 2;4 made use of the majority of pitch patterns that the literature found in the inventory of adult interrogative intonational patterns and also reported in the child-directed speech analysis, for both Spanish and Catalan. Thus, in Spanish, the children produced the same three nuclear intonation configurations $\left(\mathrm{L}+\mathrm{H}^{\star} \mathrm{H} \%, \mathrm{~L}^{\star} \mathrm{H} \%\right.$ and $\mathrm{L}+\mathrm{j}^{\star}{ }^{\star}$ $\mathrm{L} \%)$ as the adults for the yes-no interrogatives analyzed. In Catalan, the children produced three out of the four of the nuclear intonation patterns found in the adult $\mathrm{CDS}$ productions ( $\mathrm{L}+\mathrm{H}^{\star} \mathrm{H} \%, \mathrm{H}+\mathrm{L}^{\star} \mathrm{L} \%$ and $\mathrm{L}^{\star} \mathrm{H} \%$ ). Importantly, the nuclear pattern not found in the Catalan children's database, the $\mathrm{L}+{ }_{\mathrm{i}} \mathrm{H}^{\star} \mathrm{L} \%$, was the least frequent pitch contour in the CDS adults' database.

Regarding the form-meaning analysis, both the adult and the children's spontaneous data (CDS and child speech, respectively) show that there was no systematic one-to-one correspondence between pitch contours and pragmatic type. Instead, nuclear pitch configurations in interrogatives in both Spanish and Catalan can appear with different pragmatic uses in both child and child- 
directed speech data. In both languages, nearly all of the pragmatic types identified had two to four corresponding pitch configurations, and thus we cannot claim that there is just one typical intonation contour for information-seeking, confirmation-seeking, offer, or echo questions. Importantly, even though there was intonational variation within each pragmatic type, the associated intonational contours according to previous literature (see Tables 3 and 4) tended to be dominant for a particular pragmatic type. Only in the case of the Catalan child speech for echoes do we see a one hundred percent correspondence between nuclear contour type and expected pragmatic type. In all of the other cases, the distribution of intonation contours varied to some degree, either confirming predictions (e.g., $\mathrm{L}+\mathrm{H}^{\star} \mathrm{H} \%$ for offers both in Catalan and Spanish, and confirmation-seeking questions in Catalan) or demonstrating the variability of contour choice (e.g., confirmation-seeking questions in Spanish).

One of the unanticipated cases of form-meaning variability was that of confirmation-seeking questions in Spanish, which received a variety of contours attached to them. In this language, neither the adult CDS nor the child speech produced the confirmation-seeking questions with the nuclear accent contour $\mathrm{L}+\mathrm{H}^{\star} \mathrm{H} \%$ in the majority of cases as the literature previously identified. Instead, the adults produced the $\mathrm{L}+{ }_{j} \mathrm{H}^{\star} \mathrm{L} \%$ contour and the children produced the two rising contours ( $\mathrm{L}^{\star} \mathrm{H} \%$ and $\mathrm{L}+\mathrm{H}^{\star} \mathrm{H} \%$ ) with almost equal frequency. One possible explanation is that Spanish speakers are using the $\mathrm{L}+{ }_{\mathrm{j}} \mathrm{H}^{\star} \mathrm{L} \%$ contour for a variety of pragmatic types, making this a productive contour that marks default interrogativity and that can occur in numerous environments. This is similar to recent results by Armstrong (2012) showing that the default interrogative contour in Puerto Rican Spanish (PRS) can adopt a number of different pragmatic meanings, depending on context. Armstrong's work shows that Puerto Rican Spanish-speaking children use the default pattern in different contexts until they are 33 months old.

Unlike the Spanish-speaking children, the Catalan-speaking children did use the contour typically associated with the confirmation-seeking interrogatives, $\mathrm{H}+\mathrm{L}^{\star} \mathrm{L} \%$. This is most likely due to the distinctive nature of the falling accent used for these types in Catalan in comparison to the other nuclear accent patterns present for $y n$-interrogatives. Thus, even though it is important to note the flexible nature of nuclear contour usage for different pragmatic types, our data from spontaneous speech corpora provide evidence that young children use a variety of interrogative intonation patterns in a pragmatically coherent way to signal communicative intent, confirming earlier accounts (see also Cruttenden 1982; Marcos 1987). Crucially, our results show that most of the intonational formmeaning preferred associations are similar for both child speech and childdirected speech. Since there are few existing studies on the acquisition of the 
mapping between intonation and pragmatic meaning, our data represent an initial look into the early mapping patterns for Spanish and Catalan children.

Finally, these results highlight the importance of the assessment of the form-meaning correspondences for the understanding of intonational development. Further corpus-based studies as well as controlled experiments are needed to investigate the correspondences between melodic variation and the conveyance of pragmatic meanings.

Acknowledgments: The work reported in this article was presented at the Phonetics and Phonology in Iberia 2009 conference, held at Las Palmas de Gran Canaria in June 2009. The authors would like to thank the audience of this conference for their helpful comments. We also gratefully acknowledge the two anonymous reviewers for their critiques and suggestions that helped improve this paper. Additional thanks to M. Armstrong, Ll. Astruc, A. Chen, L. D’Odorico, P. Fikkert, S. Frota, C. Lleó, and K. Demuth for their feedback. A special thanks goes to Miquel Serra, Ana Ojea and María López-Ornat for letting us use the original recordings, and to the parents and children who participated in the longitudinal studies. The project was funded by grants FFI2009-07648/FILO, BFU2012-31995, and CONSOLIDER-INGENIO 2010 'Bilingüismo y Neurociencia Cognitiva CSD2007-00012' awarded by the Spanish Ministry of Science and Innovation and by project 2009 SGR 701 awarded by the Generalitat de Catalunya.

\section{References}

Anderson, Anne, Miles Bader, Ellen Gurman Bard, Elizabeth Boyle, Gwyneth Doherty, Simon Garrod, Stephen Isard, Jacqueline Kowtko, Jan McAllister, Jim Miller, Cathy Sotillo, Henry S. Thompson \& Regina Weinert. 1991. The HCRC map task corpus. Language and Speech 34. 351-366.

Armstrong, Meghan. 2012. The development of yes-no question intonation in Puerto Rican Spanish. Columbus, $\mathrm{OH}$ : The Ohio State University dissertation.

Astruc, Lluïsa, Elinor Payne, Brechtje Post, Maria del Mar Vanrell \& Pilar Prieto. 2013.

Tonal targets in early child English, Spanish, and Catalan. Language and Speech 56(2). 229-253.

Beckman, Mary E. \& Janet B. Pierrehumbert. 1986. Intonational structure in English and Japanese. Phonology Yearbook 3. 255-310.

Boersma, Paul \& David Weenink. 2009. Praat: doing phonetics by computer (Version 5.1) [Computer program]. http://www.praat.org/. (31 January, 2009).

Bolinger, Dwight. 1989. Intonation and its uses: Melody in grammar and discourse. Stanford: Stanford University Press.

Bonet, Eulàlia. 1986. L'entonació de les formes interrogatives en barceloní. Els Marges 33. 103-117. 
Carletta, Jean, Amy Isard, Stephen Isard, Jacqueline Kowtko, Gwyneth Doherty-Sneddon \& Anne Anderson. 1995. The coding of dialogue structure in a corpus. Twente Workshop on Language Technology on Corpus-Based Approaches to Dialogue Modelling. Twente: The Netherlands.

Chen, Aoju \& Paula Fikkert. 2007. Intonation of early two-word utterances in Dutch. In J. Trouvain \& W. J. Barry (eds.), XVIth International Congress of Phonetic Sciences (ICPhS), 315-320. Dudweiler: Pirrot.

Cruttenden, Alan. 1982. How long does intonation acquisition take? Papers and Reports on Child Language Development 21.112-118.

Escandell-Vidal, Maria Victoria. 1998. Intonational and procedural encoding: the case of Spanish interrogatives. In V. Rouchota \& A. Jucker (eds.), Current Issues in Relevance Theory, 169-203. Amsterdam: John Benjamins.

Estebas-Vilaplana, Eva \& Pilar Prieto. 2010. Peninsular Spanish intonation. In P. Prieto \& P. Roseano (eds.), Transcription of intonation of the Spanish Language, 17-48. München: Lincom Europa.

Fernández Ramírez, S. 1957-1959. Oraciones interrogativas españoles. Boletín de la Real Academia Española 39. 243-276.

Frota, Sonia \& Marina Vigário. 2008. The intonation of one-word and first two-word utterances in European Portuguese. Third Conference on Tone and Intonation (TIE 3), 15-17 September, Lisbon.

Gordon, Matthew. 2005. Intonational phonology of Chickasaw. In Sun-Ah Jun (ed.), Prosodic Typology: The Phonology of Intonation and Phrasing, 301-330. Oxford: Oxford University Press.

Grice, H. Paul. 1957. Meaning. Philosophical Review 66. 337-388.

Grice, H. Paul. 1975. Logic and conversation. In P. Cole \& S.L. Morgan (eds.), Syntax and semantics: Speech acts 3, 41-58. New York: Academic Press.

Grice, Martine, Mariapaola D'Imperio, Michelina Savino \& C. Avesani. 2005a. Strategies for intonation labelling across varieties of Italian. In Sun-Ah Jun (ed.), Prosodic Typology: The Phonology of Intonation and Phrasing, 362-389. Oxford: Oxford University Press.

Grice, Martine, Stefan Baumann \& Ralf Benzmüller. 2005b. German Intonation in Autosegmental-Metrical Phonology. In Sun-Ah Jun (ed.), Prosodic Typology: The Phonology of Intonation and Phrasing, 55-83. Oxford: Oxford University Press.

Gussenhoven, Carlos. 2002. Intonation and interpretation: phonetics and phonology. In B. Bel \& I. Marlien (eds.), Speech Prosody 2002, 47-57. Aix-en-Provence: ProSig and Université de Provence Laboratoire Parole et Language.

Hirschberg, Julia. 2002. The pragmatics of intonational meaning. In B. Bel \& I. Marlien (eds.), Speech Prosody 2002, 65-68. Aix-en-Provence: ProSig and Université de Provence Laboratoire Parole et Language.

Holzman, Mathilda. 1972. The use of interrogative forms in the verbal interaction of three mothers and their children. Journal of Psycholinguistic Research 1(4). 311-336.

House, David. 2002. Intonational and visual cues in the perception of interrogative mode in Swedish. In J. H. L. Hansen \& B. Pellow (eds.), 7th International Conference on Spoken Language Processing (ICSLP), 1957-1960. Denver, Colorado.

House, David. 2003. Hesitation and interrogative Swedish intonation. Phonum 9. 185-188.

Hualde, José Ignacio \& Pilar Prieto. (to appear in 2015). Intonational variation in Spanish. In Sónia Frota and Pilar Prieto (eds.), Intonational variation in Romance. Oxford: Oxford University Press. 
Jun, Sun-Ah (ed.). 2005. Prosodic typology: The phonology of intonation and phrasing. Oxford: Oxford University Press.

Ladd, D. Robert. 2008 [1996]. Intonational phonology, $2^{\text {nd }}$ edn. Cambridge: Cambridge University Press.

Lleó, Conxita \& Martin Rakow. 2011. Intonation targets of yes-no questions by Spanish and German monolingual and bilingual 2;0- and 3;0-year-olds. In T. Kupisch \& E. Rinke (eds.), The development of grammar: Language acquisition and diachronic change (Hamburger Studies on Multilingualism 11), 213-234. Amsterdam/Philadelphia: John Benjamins.

MacWhinney, Brian. 1992. The CHILDES database. Dublin, OH: Discovery Systems.

Marcos, Haydée. 1987. Communicative functions of pitch range and pitch direction in infants. Journal of Child Language 14. 255-268.

Navarro Tomás, Tomás. 1968. Manual de entonación española. New York: Hispanic Institute in the United States.

Pierrehumbert, Janet. 1980. The phonology and phonetics of English intonation. Cambridge, MA: MIT dissertation.

Pierrehumbert, Janet \& Julia Hirschberg. 1990. The meaning of intonational contours in the interpretation of discourse. In P. Cohen, J. Morgan \& M. Pollack (eds.), Intentions in Communication, 271-311. Cambridge, MA: MIT Press.

Prieto, Pilar. 2002. Entonació. In J. Solà, M.R. Lloret, J. Mascaró \& M. Pérez-Saldanya (eds.), Gramàtica del català contemporani 1, 395-462. Barcelona: Edicions 62.

Prieto, Pilar \& Maria del Mar Vanrell. 2007. Early intonational development in Catalan. In J. Trouvain \& W. J. Barry (eds.), XVIth International Congress of Phonetic Sciences (ICPhS), 309-314. Dudweiler: Pirrot.

Prieto, Pilar, Ana Estrella, Jill Thorson \& Maria del Mar Vanrell. 2012. Is prosodic development correlated with grammatical development? Evidence from emerging intonation in Catalan and Spanish. Journal of Child Language 39(2). 221-257.

Prieto, Pilar, Joan Borràs-Comes, Verònica Crespo-Sendra, Jill Thorson \& Maria del Mar Vanrell. 2011. Entonación y pragmática en los enunciados interrogativos del español en habla dirigida a niños. Oralia 14. 227-255.

Prieto, Pilar. 2014. The intonational phonology of Catalan. In Sun-Ah Jun (ed.), Prosodic Typology 2. The Phonology of Intonation and Phrasing. Oxford: Oxford University Press. 43-80.

Quilis, Antonio. 1985. Entonación dialectal hispánica. Lingüística Española Actual 7. 145-190.

Quilis, Antonio. 1993. Tratado de fonología y fonética españolas. Madrid: Gredos.

Rose, Yvan \& Brian MacWhinney. 2014. The PhonBank initiative. In J. Durand, U. Gut \& G. Kirstoffersen (eds.), Handbook of Corpus Phonology. Oxford: Oxford University Press.

Rose, Yvan, Brian MacWhinney, Rodrigue Byrne, Gregory Hedlund, Keith Maddocks, Philip O’Brien \& Todd Wareham. 2006. Introducing Phon: A software solution for the study of phonological acquisition. In D. Bamman, T. Magnitskaia \& C. Zaller (eds.), 30th Annual Boston University Conference on Language Development (BUCLD), 489-500. Somerville, MA: Cascadilla Press.

Santos, Ana Lúcia \& Mata, Ana Isabel. 2008. Between form and meaning: using intonation cues to identify confirmation-seeking requests. Third TIE Conference on Tone and Intonation (TIE 3), Lisbon, 15-17 September.

Savino, Michelina \& Martine Grice. 2011. The perception of negative bias in Bari Italian questions. In S. Frota, P. Prieto \& G. Elordieta (eds.), Prosodic categories: production, perception and comprehensio, 187-206. London/New York: Springer Verlag. 
Searle, John R. 1969. Speech acts: An essay in the philosophy of language. London: C.U.P.

Sosa, Juan Manuel. 1999. La entonación del español: Su estructura fónica, variabilidad y dialectología. Madrid: Cátedra.

Vanrell, Maria del Mar, Ignasi Mascaró, Francesc Torres-Tamarit \& Pilar Prieto. 2013. Intonation as an encoder of speaker's certainty: Information and confirmation yes-no questions in Catalan. Language and Speech 56(3). 163-190.

Venditti, Jennifer J. 2005. The J_ToBI Model of Japanese Intonation. In Sun-Ah Jun (ed.), Prosodic Typology: The Phonology of Intonation and Phrasing, 172-200. Oxford: Oxford University Press.

Venditti, Jennifer J., Julia Hirschberg \& Jackson Liscombe. 2006. Intonational cues to student questions in tutoring dialogs. Interspeech (ICSLP), 549-552. Pittsburgh, PA.

Vigário, Marina \& Sonia Frota. 2003. The intonation of Standard and Northern European Portuguese: A comparative intonational phonology approach. [Special Issue on Portuguese Phonology]. Journal of Portuguese Linguistics 2(2). 115-137.

Ward, Gregory \& Julia Hirschberg. 1985. Implicating uncertainty: The pragmatics of fall-rise intonation. Language 64(1). 747-776.

Wilson, Deirdre \& Dan Sperber. 1993. Linguistic form and relevance. Lingua 93. 1-25.

Wong, Wai Yi P., Marjorie K. M. Chan \& Mary E. Beckman. 2005. An autosegmental-metrical analysis and prosodic annotation conventions for Cantonese. In Sun-Ah Jun (ed.), Prosodic Typology: The Phonology of Intonation and Phrasing, 271-300. Oxford: Oxford University Press. 
Copyright of Probus: International Journal of Latin \& Romance Linguistics is the property of De Gruyter and its content may not be copied or emailed to multiple sites or posted to a

listserv without the copyright holder's express written permission. However, users may print, download, or email articles for individual use. 